\title{
Post-merger Price Dynamics Matters, So Why Do Merger Retrospectives Ignore It?
}

\author{
Franco Mariuzzo ${ }^{1} \cdot$ Peter L. Ormosi ${ }^{2}$ D
}

Published online: 29 July 2019

(c) The Author(s) 2019

\begin{abstract}
The overwhelming majority of retrospective merger studies pool the post-merger data to estimate the average price effect of the merger. Pooled post-merger estimates ignore key information about price dynamics and are unable to identify if post-merger prices revert to pre-merger levels within the same time period. We provide evidence - from a meta-analysis of over 600 previous market-level price effect estimates, and a set of Monte Carlo experiments-that using pooled models often leads to erroneous conclusions: for example by wrongly concluding that the merger increased prices, even when this price increase was only temporary.
\end{abstract}

Keywords Mergers $\cdot$ Merger retrospectives $\cdot$ Meta study $\cdot$ Monte Carlo simulations

JEL Classification codes C51 $\cdot \mathrm{K} 21 \cdot \mathrm{L} 49$

\section{Introduction}

The price effect of past mergers has received increasing attention since the early 1990s. The recent upsurge in the number of such studies generated a considerable body of evidence of the price effect of mergers. Kwoka $(2013,2014)$ identified more than 60 US studies that looked at the price effect of mergers. Mariuzzo et al. (2016) reviewed another 20 similar European studies.

Methodologically, these studies are relatively homogeneous. They use standard difference in-differences type models, and they vary mainly in the way the

Peter L. Ormosi

p.ormosi@uea.ac.uk

Franco Mariuzzo

f.mariuzzo@uea.ac.uk

1 School of Economics and Centre for Competition Policy, University of East Anglia, Norwich NR4 7TJ, UK

2 Norwich Business School and Centre for Competition Policy, University of East Anglia, Norwich NR4 7TJ, UK 
counterfactual is constructed. The objective of our paper is to focus on a specific empirical aspect of these studies, the handling of post-merger time-periods. The specification of the estimated model plays a cardinal role in how the results should be interpreted. Most previous studies estimate over-time average post-intervention price-effects; these studies overlook post-merger price dynamics. In general, in many causal inference studies the post-intervention dynamics of the outcome variable would not matter. However, there are equally many situations where evidence on this variation is exactly what the researcher should be aiming to get. Estimating the price effect of mergers is one of these. ${ }^{1}$

Estimating the over-time average price effect of mergers is counter-intuitive for two main reasons. First, merger guidelines agree that no intervention is needed if the post-merger price increase disappears within a reasonable amount of time, for example because of new entry. The US Horizontal Merger Guidelines say: "The Agency will consider entry to be timely so long as it would deter or counteract the competitive effects of concern within the two year period and subsequently." 2 Similarly, the European Commission's guidelines on the Merger Regulation state: "The Commission examines whether entry would be sufficiently swift and sustained to deter or defeat the exercise of market power. What constitutes an appropriate time period depends on the characteristics and dynamics of the market, as well as on the specific capabilities of potential entrants. However, entry is normally only considered timely if it occurs within two years." 3 Of course for entry to occur, a potential entrant would have to find such entry profitable, and the extent of entry would have to be such that prices would revert to (or remain at) pre-merger levels. Retrospective studies could verify whether these conditions are fulfilled after a merger. However, entry and its effects are a gradual process (prices might take some time to drop or to increase), which requires looking at the dynamics of post-merger prices in order to identify whether pre-merger expectations about entry-and the effect of entry-were correct.

Second, merger retrospectives are typically conducted to inform policy-makers whether a merger decision was correct or not. For this reason the conclusion as to how prices change post-merger is crucial. The estimation of the average post-merger price-effect requires a different empirical model than estimating annual effects. Is it possible that the two empirical models return different evidence on the price effects of the merger? We show in this paper that the likelihood of making the wrong conclusion is very high if the wrong empirical model is used.

The purpose of this paper is not to stipulate that longer-term studies are better suited for post-merger price evaluations, although given merger policy guidelines,

\footnotetext{
1 The importance of controlling for dynamics in difference-in-differences studies, is not new to the economics literature. A good example of the bias that can be generated by using a misspecified model is given by Wolfers's's (2006) study of the causal effect of the implementation of unilateral divorce laws in the US on divorce rates.

${ }^{2}$ U.S. Department of Justice \& Federal Trade Commission, Horizontal Merger Guidelines (2010), available at https://www.justice.gov/atr/horizontal-merger-guidelines-08192010, accessed 25/09/2017.

3 Guidelines on the assessment of horizontal mergers under the Council Regulation on the control of concentrations between undertakings (2004/C 31/03), available at http://eur-lex.europa.eu/LexUriServ/ LexUriServ.do?uri=OJ:C:2004:031:0005:0018:en:PDF, accessed 25/09/2107.
} 
it appears appropriate to include at least two post-merger years in any merger evaluation. Instead we argue that even if the available data are relatively short-spanning (two years), one should still look at the dynamics of price effects (for example the effect in the first and in the second year separately) and not only the over-time average as it is currently done in the majority of studies. The difference is easy to see. Take a merger, that increases prices by 10 percent in the year following the merger but then prices revert to the pre-merger level in the second post-merger year. Currently, only one in five merger retrospectives estimate these annual price effects and would conclude that post-merger prices reverted to pre-merger levels by the end of the second year. Four in five studies would estimate an over time average. In this case this would imply a 5 percent price increase and could lead to the conclusion that the merger was anticompetitive, and that the intervention was insufficient. ${ }^{4}$

There is surprisingly little empirical work on the dynamics of how markets evolve post-merger, and whether the antitrust agency's expectations at the time of the merger came true (for example, did entry happen as expected and did it reduce prices as predicted?) A notable exception is a set of annually conducted studies by the UK Competition Commission, which used to collect qualitative evidence on how market characteristics (other than just price) evolved over a longer post-merger period. ${ }^{5}$ With regard to specific mergers, Winston et al. (2011) look at the longrun effect of two railroad mergers. They estimate how prices evolved (year-by-year) post-merger and find that despite the short-term increases in price the mergers had no effect in the long-run on prices and welfare. Looking at mergers in the US market for bank deposits Focarelli and Panetta (2003) arrive at similar conclusions: mergers create higher prices in the more immediate aftermath of the merger, but this effect later disappears. ${ }^{6}$

We contribute to the rich body of merger retrospective studies in an important way, by pointing out how inappropriately designed empirical models, irrespective of data availability, will mask important information on the price effect of mergers. First we formalise the problem and argue that pooling together all post-merger time periods will provide price-effect estimates that are the average of the per period (annual) effects with a standard error that is lower than the standard errors of the annual price effects (at least under the assumption of non-positive correlation). This difference in standard errors has an important role to play in our main argument.

We attempt to demonstrate the effect of choosing the wrong model by employing a meta-analysis of more than 600 previous market-level price-effect estimates. Where estimates were available on price dynamics—e.g. where a study estimated

\footnotetext{
${ }^{4}$ Of course, it is an equally important question: what happens if the merger is followed by a temporary price increase, which is dissipated within two years following the merger, for example because of new entry. Implicitly, current merger guidelines overlook this temporary consumer welfare loss if entry is sufficiently timely so that consumers are not significantly harmed by the temporary loss of competition.

5 These can be found in the old UK Competition Commission's archives, see for example here: https:// goo.gl/soj2xk.

${ }^{6}$ Of course when the time period post merger is too long there is more of a risk of picking confounding effects. However, this is an issue shared both by pooled and unpooled models. In light of this in our analysis we concentrate on a medium-run period of time.
} 
annual effects-we were able to show how far off the over-time average estimates would have been. On the other hand, where only over-time average estimates were reported in the studies (this is what we refer to as inappropriate model choice), we could not re-construct the per-period variation in prices, therefore we turned to a set of Monte Carlo simulations and calibrations. These simulations show that models that estimate an average post-merger price effect are more likely to lead to erroneous conclusions (e.g. concluding that the merger increased prices, even when it did not, or concluding that the merger did not increase prices even when it did).

The paper is structured the following way. First, we describe how previous papers have handled post-merger price dynamics and show that this has been typically ignored. We then provide a discussion of the difference between the pooled and unpooled time period models. This is followed by a set of simulations and calibrations to demonstrate the magnitude of the problem, and we conclude with policy recommendations.

\section{Post-merger Price-Dynamics in Previous Merger Retrospectives}

We surveyed a large body of retrospective merger studies reviewed by Kwoka (2013) and Mariuzzo et al. (2016). ${ }^{7}$ We focus on one aspect of these studies: the econometric specification for estimating post-merger price effects. The main selection conditions for our sample are: that ex-post percentage price-effect estimates are provided in the study, that their standard errors can be recovered, and that the time span of the data is identifiable. All of the studies in our sample used reduced-form causal inference models (typically difference-in-differences).

Our sample contains price-effect estimates of 68 mergers (which are discussed in 39 papers that are either published or in circulation as working paper at the time of our analysis). Of the 68 mergers, 52 are US mergers, and 16 EU. ${ }^{8}$ Some of the retrospective merger papers report estimates for the effect of the given merger on a range of different product and geographical markets. This gives us a sample of 626 market-level price-effect estimates. ${ }^{9}$

We distinguish between two types of studies. The first, and by far the most common, treats the post-merger period as a single period, and pools all post-merger price observations, and thus estimates the average effect of the merger over the post-merger period. We call this set of studies "pooled studies". The second group controls for price observations year by year, and estimates annual post-merger price changes ("unpooled studies").

More than $80 \%$ of the 68 merger studies have pooled the post-merger time periods and estimated an average price effect for the entire post-merger period. Similarly most of the product/geographic market-level price effects - 558 out of 626 -are

\footnotetext{
7 The full list of these studies is provided in the "Appendix". The data is available at: https:/github.com/ PeterOrmosi/merger-dynamic.

8 Kwoka (2013, 2014) and Mariuzzo et al. (2016) provide more information about these mergers.

9 We provide descriptive information on these estimates in the "Appendix".
} 
Table 1 Number and fraction of pooled and unpooled studies by journals

\begin{tabular}{llllll}
\hline Journal & $\#$ & \# of pooled & \# of unpooled & \% of pooled & \% of unpooled \\
\hline AM ECON REV & 8 & 6 & 2 & 0.75 & 0.25 \\
GAO & 7 & 7 & 0 & 1.00 & 0.00 \\
J INDUS ECON & 6 & 5 & 1 & 0.83 & 0.17 \\
J L AND ECON & 6 & 4 & 2 & 0.67 & 0.33 \\
INT'L J ECON BUS & 6 & 6 & 0 & 1.00 & 0.00 \\
WP & 6 & 6 & 0 & 1.00 & 0.00 \\
FTC & 3 & 2 & 1 & 0.67 & 0.33 \\
AM ECON J-ECON POL & 3 & 3 & 0 & 1.00 & 0.00 \\
EUROPEAN COMMISSION & 2 & 2 & 0 & 1.00 & 0.00 \\
J TRANSP ECON POLICY & 2 & 2 & 0 & 1.00 & 0.00 \\
MANAG DECIS ECON & 2 & 2 & 0 & 1.00 & 0.00 \\
\hline
\end{tabular}

estimated by pooling the post-merger period data. The remaining 68 market-level estimates-10 merger studies that were published in 5 papers-are from unpooled studies. More detailed description of the data is given in the "Appendix".

Another striking figure in the data is that more than $80 \%$ of these merger studies have estimated the average price effect within less than two years of the merger. There are two problems with this. First, estimating an over-time average completely masks the dynamics of post-merger prices, and as such is inadequate for evaluating the effectiveness of merger control. Second, it does not allow for a full assessment of how prices evolve over time. Both the EU and the US guidelines emphasise that a merger may not be considered problematic if appropriate entry happens within two years of the merger, therefore the knowledge of how prices changed within two years cannot fully answer the question of whether a merger decision was effective.

Table 1 shows the number of mergers that have been evaluated in retrospective studies published in the most frequent outlets (two or more mergers covered). The American Economic Review (including Papers and Proceedings) published the largest number of merger studies, most use the pooled model. The Journal of Law and Economics has the highest propensity of studies that use the unpooled model.

An interesting question-although somewhat tangential to our main story-is whether the choice of the model (pooled or unpooled) is random with respect to the type of mergers. As a simple test, we compare the distribution of price effect estimates for the two groups. A comparison at the market/product level of estimates (626 estimates), using a two-sample Kolmogorov-Smirnov (KS) equality-of-distributions test, provides evidence that the two distributions differ. However, when we collapse the samples to merger-level estimates (68 estimates) and repeat the twosample KS test we find that the null hypothesis of equality-of distributions is not rejected. The focus of this paper is on the dynamics of price changes and not on their general distribution, however the evidence that the pooled and unpooled distributions do not differ at the merger level could be interpreted as a sign that the mergers in the two groups are roughly comparable. Again, this is not required for our main point about using the right estimation model, but it helps illustrate our point. 
Table 2 Meta analysis results - price effects within two years of the mergers (relative to the year prior to the merger)

\begin{tabular}{|c|c|c|c|c|c|c|c|}
\hline \multirow[t]{2}{*}{ Period } & \multicolumn{3}{|l|}{ Pooled } & \multirow[t]{2}{*}{ Period } & \multicolumn{3}{|l|}{ Unpooled } \\
\hline & Mean & SE & Count & & Mean & SE & Count \\
\hline \multicolumn{8}{|c|}{ Unweighted } \\
\hline \multirow[t]{2}{*}{$\leq 2$ years } & $3.240 * * *$ & 0.648 & 52 & First year & $5.388 * *$ & 2.630 & 10 \\
\hline & & & & Second year & -1.040 & 2.000 & 10 \\
\hline \multicolumn{8}{|c|}{ Weighted by $t$-stat } \\
\hline \multirow[t]{2}{*}{$\leq 2$ years } & $5.044 * * *$ & 0.269 & 52 & First year & $5.280 * * *$ & 2.040 & 10 \\
\hline & & & & Second year & -0.782 & 1.554 & 10 \\
\hline \multicolumn{8}{|c|}{ Weighted by journal impact factor } \\
\hline \multirow[t]{2}{*}{$\leq 2$ years } & $4.607 * * *$ & 1.355 & 52 & First year & $5.989 * * *$ & 2.170 & 10 \\
\hline & & & & Second year & -0.826 & 1.430 & 10 \\
\hline \multicolumn{8}{|c|}{ Weighted by journal citations } \\
\hline \multirow[t]{2}{*}{$\leq 2$ years } & $5.149 * *$ & 2.047 & 52 & First year & 3.301 & 2.069 & 10 \\
\hline & & & & Second year & -1.708 & 1.640 & 10 \\
\hline
\end{tabular}

$* p<0.10, * * p<0.05, * * * p<0.01$

\subsection{Pooled and Unpooled Post-merger Price Effect Estimates}

To summarise previous price-effect estimates we adopt a meta-analysis approach. For each retrospective merger study we take note of the estimated difference-indifferences (DiD) coefficients of percentage price changes and their corresponding standard errors. The rule that we follow in recording the relevant estimates is the following. If the retrospective study presented more than one regression for each market (often included in the study as part of robustness checks), our strategy was to include the average DiD estimates (and average standard error estimates) over these regressions. When the standard error was not reported in the merger study we proxied it from any useful information that was available. We often used the stars on the significance of the coefficients to retrieve the standard errors. ${ }^{10}$

Table 2 shows the result of our meta-analysis, when the estimates are collapsed by mergers (and not by product/market). ${ }^{11}$ The pooled column shows the price effects that were estimated with the use of models that pool data for up to two years after the merger. The unpooled column also shows the estimated effects within two years from the merger but only for studies where the first, and the second year effects were separately estimated. Both of these price effect estimates are relative

\footnotetext{
10 For example, if the DiD coefficient was significant at $1 \%$ (typically indicated with three stars), we generated the proxied standard error as ratio between the estimate and critical value 2.575. When it was significant at 5\% we used as denominator the mid-point between 1.96 and 2.575, and when the significance was at $10 \%$ the division was by the mid-point between 1.645 and 1.96 . Finally, in case of nonsignificance the value chosen as the denominator was the mid-point between 0.8225 (itself a mid-point between 0 and 1.645) and 1.645.

11 The market level summary of the meta study is given in the "Appendix".
} 
to the pre-merger price. The first section displays the unweighted combined price effects of mergers. The second section describes the combined estimates where we use the t-value of the estimated percentage price effect as weights. The idea is that observations with larger t-values should weigh more in combining the results from different merger studies. ${ }^{12}$ The third section contains the meta price effect where we weight each estimate by the number of citations the publication received up to that day (as shown on Google Scholar on 20 September 2017). Finally, in the fourth section, we conduct a similar exercise and obtained from ReserchGate the impact factor of the publications for the most recent year, 2015/16. For manuscripts and working papers, for which no such information was available, we associate a minimal weight value of 0.3 .

The results from our meta-analysis reveal an interesting pattern. When the unpooled model was used-post-merger annual estimates are provided-the postmerger price increase, on average, disappeared by the second year following the merger (prices reverted to pre-merger levels). When the pooled model was used, the unweighted estimate is close to the average of the two years following the merger. This is in line with what we will show formally later: that the pooled model delivers the arithmetic mean of the estimates from the unpooled model. If we accept that the selection of the model-pooled or unpooled - is independent of the merger, this would suggest that had the 10 studies that used the unpooled model relied on the pooled model, the estimates would have been similar to the estimates found in the pooled model.

More importantly, this suggests that on average, the use of the pooled model, as has been done dominantly in previous literature, is more likely to conclude wrongly that the merger increased prices, even if the price increase disappeared by the end of the second post-merger year. This matters because the policy interpretation of the two findings are contrastingly different. A merger with a price increase that disappears within two years would not be subject to intervention, but a merger that leads to a price increase over the first two years would. ${ }^{13}$

The point we are trying to emphasise here is not about using longer spanning data-although two post-merger years is a minimum to be in line with merger guidelines. But to make sure that the dynamics of price changes are identifiable from the estimated model. One of the main reasons for conducting merger retrospectives is to improve our understanding of the effectiveness of merger control (Kwoka 2013). On this ground, one would expect the merger retrospective to provide an idea of whether the antitrust authority made the right decision. For example, if prices increased after the merger it might be interpreted as an error by the antitrust authority. On the other hand, if the estimates show that post-merger prices converge to zero within a reasonable length of time, then the antitrust authority did not make an error even if the initial price effect was significantly positive. Estimating the post-merger

\footnotetext{
12 This is very similar to inverse variance weights.

13 Of course, the magnitude of the average price effects presented in Table 2 is small enough to suggest that they would have probably passed under some sort of 'safe harbour' rule. Nevertheless, our point is not to argue for or against the merger decisions, rather to draw light to a methodological flaw in the expost studies.
} 
over-time average does not allow us to analyse price dynamics. Instead, it could wrongly conclude that merger control was too lax-even in cases where post-merger prices revert to pre-merger levels by the end of the second post-merger year. In the following section we formulate the difference between estimating average or annual post-merger price effects.

\section{A Conceptual Framework}

For each market $m$ and time $t$, let $p_{m t}$ denote the price of a unit (product or firm) and $W_{m}$ the treatment dummy variable (firm/product involved in the merger). $T_{L}$ periods are recorded before-and $T_{R}$ after-a merger that takes place in period 0 . Let $d_{k}$ represent a dummy variable that takes the value 1 every $k$ th period after the merger, and zero otherwise. The sum of the post-treatment dummy variables is used in the pooled model, and is denoted as $D_{T_{R}} \equiv \sum_{k=1}^{T_{R}} d_{k}$. Furthermore, indicate with $\tau=1, \ldots, T$ fragments of time within a period $k$; for example $\tau$ could measure days and $k$ years-when we have daily price data but are estimating yearly price effects post treatment. Examining the yearly effects for $T_{R}$ periods following the merger and one period pre-merger $\left(T_{L}=1\right)$, we can express the unpooled linear econometric equation for prices as:

$$
\begin{gathered}
p_{m t}=\beta_{0}+\beta_{1} W_{m}+\sum_{k=1}^{T_{R}}\left(\gamma_{k} d_{k}+\delta_{k} d_{k} W_{m}\right)+\alpha_{m}+\lambda_{\tau}+\varepsilon_{m t}, \\
m=\{1,2, \ldots, M\} ; t=\left\{-T, \ldots,-1,1, \ldots, T \times T_{R}\right\},
\end{gathered}
$$

where $\delta_{k}$ are the difference-in-differences (DiD) estimators for each year after the merger; $\alpha_{m}$ is a market-specific unobservable variable; and $\lambda_{\tau}$ is a set of controls that capture possible seasonality in the data. If we assume that the dataset is balanced, the total time observations are $T \times\left(T_{R}+1\right)$.

As was discussed earlier, what is typically estimated in most merger retrospective studies is a slightly different model, with time-period post-merger dummy variables replaced by a pooled period post-merger dummy:

$$
p_{m t}=\beta_{0}+\beta_{1} W_{m}+\Gamma_{T_{R}} D_{T_{R}}+\Delta_{T_{R}} D_{T_{R}} W_{m}+\alpha_{m}+\lambda_{\tau}+\varepsilon_{m t},
$$

where the DiD estimator for a pooled period of length $T_{R}$ is denoted with $\Delta_{T_{R}}$. Equation (1b) is what we refer to as the pooled model. Equation (1b) can be seen as a restricted version of Eq. (1a) once we impose $\gamma_{1}=\gamma_{2}=\cdots=\gamma_{T_{R}}=\Gamma_{T_{R}}$, along with the further restriction $\delta_{1}=\delta_{2}=\cdots=\delta_{T_{R}}=\Delta_{T_{R}}$; but as we will show later, even in this case standard errors may differ.

If we consider an analysis that is restricted to only two years after the merger $\left(T_{R}=2\right)$ and one year before the merger $\left(T_{L}=1\right)$, and use the unpooled model, we have that the $\mathrm{DiD}$ coefficient for the second year from the above equation, when separate time period dummy variables are included, can be written as: 


$$
\begin{aligned}
\delta_{2}= & {\left[E\left(p_{m t} \mid W_{m}=1, d_{2}=1\right)-E\left(p_{m t} \mid W_{m}=0, d_{2}=1\right)\right]-} \\
& -\left[E\left(p_{m t} \mid W_{m}=1, d_{2}=0\right)-E\left(p_{m t} \mid W_{m}=0, d_{2}=0\right)\right] .
\end{aligned}
$$

For two periods after the merger the pooled model DiD estimator is:

$$
\begin{aligned}
\Delta_{2}= & \left(E\left[p_{m t} \mid W_{m}=1,\left(d_{1}+d_{2}\right)=1\right]-E\left[p_{m t} \mid W_{m}=0,\left(d_{1}+d_{2}\right)=1\right]\right)- \\
& -\left(E\left[p_{m t} \mid W_{m}=1,\left(d_{1}+d_{2}\right)=0\right]-E\left[p_{m t} \mid W_{m}=0,\left(d_{1}+d_{2}\right)=0\right]\right) .
\end{aligned}
$$

What are the implications, for the ex-post merger analysis, of using a period-byperiod dummy variable (unpooled) version rather a pooled period dummy variable model?

Continuing with the simplifying example where we focus only on the two periods that follow the merger, let us assume that there is a price increase in the first period- $\delta_{1}>0$ - but then prices revert to pre-merger levels in the second period: $\delta_{2}=0$. This is an example of a merger that would be considered unharmful because the price effect would have vanished after one year, perhaps because of entry.

Suppose that we have estimated the parameters $\widehat{\Delta}_{2}, \widehat{\delta}_{1}$, and $\widehat{\delta}_{2}$ with the use of the two different specifications. In "Appendix B" we show that the restricted estimator $\widehat{\Delta}_{2}$ is equal to the average of the yearly time period parameters, $\left(\widehat{\delta}_{1}+\widehat{\delta}_{2}\right) / 2$. Then, on the assumption that the central limit theorem holds, the time period estimators for a sample of size $N=T \times(K+1) \times M$ have the following probability distributions: $\hat{\delta}_{1} \sim N\left(\delta_{1}, \sigma_{\delta_{1}}^{2} / N\right), \widehat{\delta}_{2} \sim N\left(\delta_{2}, \sigma_{\delta_{2}^{2}} / N\right)$, which leads to $\widehat{\Delta}_{2} \sim N\left(\left(\delta_{1}+\delta_{2}\right) /\right.$ $\left.2, \sigma_{\Delta_{2}}^{2} / N\right)$, with $\sigma_{\Delta_{2}}^{2}=1 / 4\left(\sigma_{\delta_{1}}^{2}+\sigma_{\delta_{2}}^{2}+2 \sigma_{\delta_{1} \delta_{2}}\right)$. With the use of the pooled model, a merger retrospective could conclude that a merger was harmful and that intervention was insufficient, if $\Delta_{2}>0$. With the use of the unpooled model one can identify the dynamics of post-merger prices, and would only conclude that the merger was harmful if prices are still above the pre-merger level by the second period: if $\delta_{2}>0$. Both cases can be tested empirically. Given the asymptotic normality of the parameters, which follows the central limit theorem, the probability values are:

$$
\operatorname{Pr}\left(Z_{\text {unpooled }}>\frac{\widehat{\delta}_{2}}{\hat{\sigma}_{\delta_{2}} / \sqrt{N}}\right), \quad \operatorname{Pr}\left(Z_{\text {pooled }}>\frac{\left(\hat{\delta}_{1}+\hat{\delta}_{2}\right) / 2}{\hat{\sigma}_{\Delta_{2}} / \sqrt{N}}\right) .
$$

Assume a simple case, where in both periods we have a small, 1 percent price increase $\left(\hat{\delta}_{1}=0.01, \widehat{\delta}_{2}=0.01\right)$, and standard deviations $\widehat{\sigma}_{\delta_{1}}=\widehat{\sigma}_{\delta_{2}}=0.1$. Assume also that our sample size is $N=200$. Under the assumption of independence between $\hat{\delta}_{1}$ and $\hat{\delta}_{2}, \sigma_{\delta_{1} \delta_{2}}=0$, we would conclude that the merger increases prices under the pooled, but not the unpooled model: 


$$
\begin{aligned}
2 & \times \operatorname{Pr}\left(Z_{\text {unpooled }}>\frac{0.01}{\frac{0.1}{\sqrt{200}}}\right)=0.159>0.05, \quad 2 \times \operatorname{Pr}\left(Z_{\text {pooled }}>\frac{0.01}{\frac{0.07}{\sqrt{200}}}\right) \\
& =0.043<0.05 .
\end{aligned}
$$

The purpose of this simple, back of the envelope example, is to highlight the importance of carefully choosing which model to use. To demonstrate further how much it matters, we examined all of the studies in our sample, where the unpooled model was used to ex-post identify the effect of mergers. ${ }^{14}$ Using the above method we then re-estimated these merger effects but now using the pooled model. The purpose of this exercise is to demonstrate the prevalence of making an erroneous conclusion on the evaluated merger, where the researcher (wrongly) chooses the pooled model.

For each merger that was analysed in each paper we report in Table 3 the effect that was estimated in the original paper for the first and the second year following the merger (relative to the pre-merger price), together with their standard errors (columns $\delta_{1}$ and $\delta_{2}$ ). As was mentioned earlier, where more than one models was estimated for each merger (different treatment and control groups, or different specifications) we report an average (unweighted) effect and standard error. ${ }^{15}$ The table also shows what the price effect and its standard error would have been had the authors of the respective studies (wrongly) used a pooled model (column $\Delta_{2}$ ). Not having access to the original data, to calibrate the 'pooled' standard errors, we rely on the assumption that the annual estimates are independent (their covariance is zero). ${ }^{16}$

The table shows (dark grey) that in four out of the ten studies, the final conclusion of the study would have been different under the pooled model. For example, Winston et al (2011) estimated that post-merger prices would have reverted to premerger levels by the second year after the merger. Had the authors used the pooled model (column $\Delta_{2}$ ), they would have wrongly concluded that the merger led to a price-increase. In Kemp et al. (2012) and in Hosken et al. (2011) the authors estimated that after an initial price drop after the merger, prices increased back to premerger levels in the second post-merger year. Had they used a pooled model, they would have wrongly concluded that both mergers would have reduced post-merger prices. We also highlight (in lighter grey) the studies, where using the pooled model would have produced estimates with higher statistical power (become more significant). For example Schumann et al (2011) estimated a drop in post-merger prices both in the first and the second year after the merger. This was significant at $95 \%$. Had the authors used a pooled model, their results would have shown significance at $99 \%$.

\footnotetext{
${ }^{14}$ As we explain below, from the pooled studies we cannot infer annual price-variation so we cannot calibrate what the results would have been under the unpooled model-specification.

${ }^{15}$ As the purpose of this exercise is to demonstrate our analytical point, this should not affect our key findings. We could equally report a full list of all estimates reported in each study to demonstrate the same point.

${ }^{16}$ We have also re-estimated these studies under the assumption of unit correlation and got qualitatively similar results.
} 


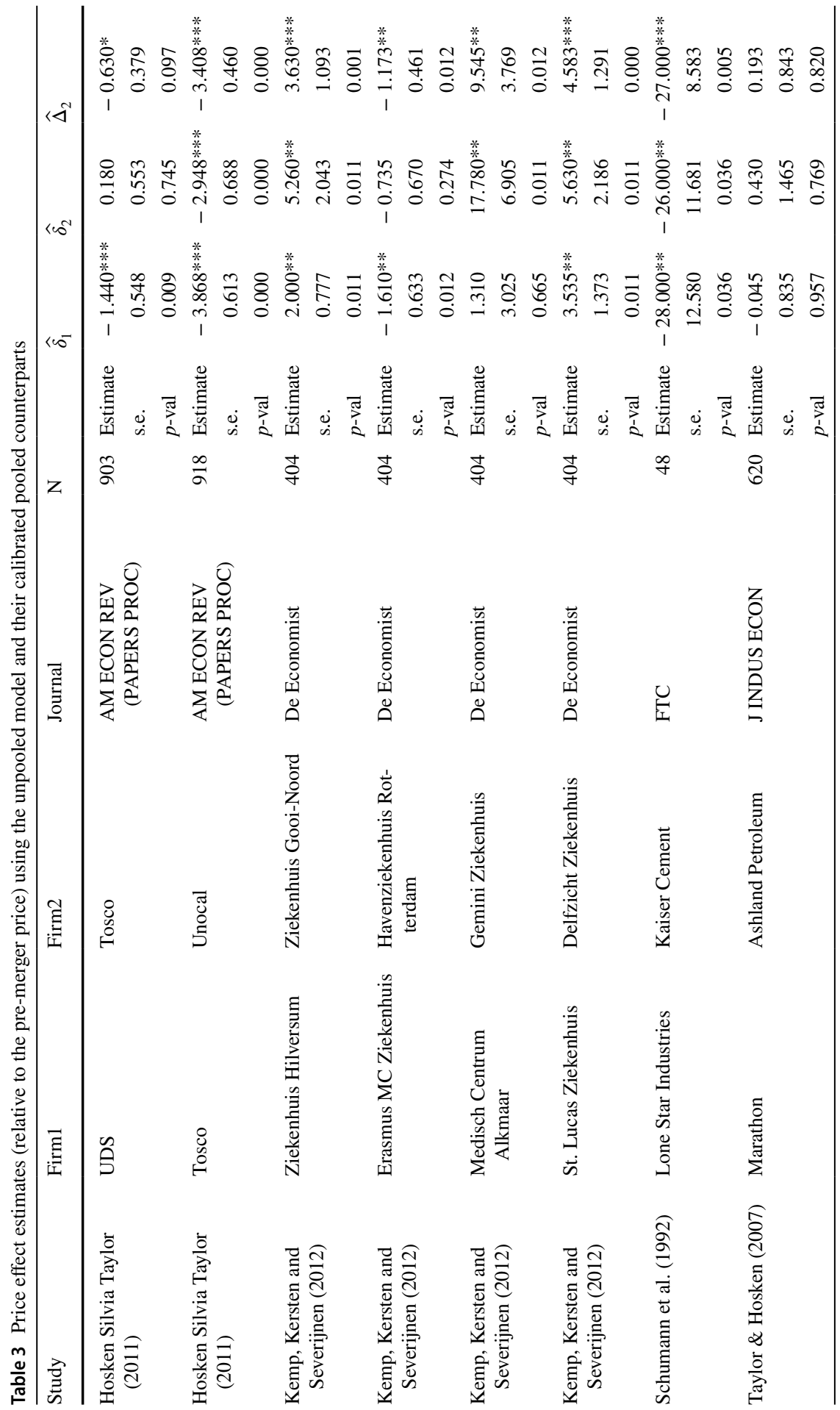




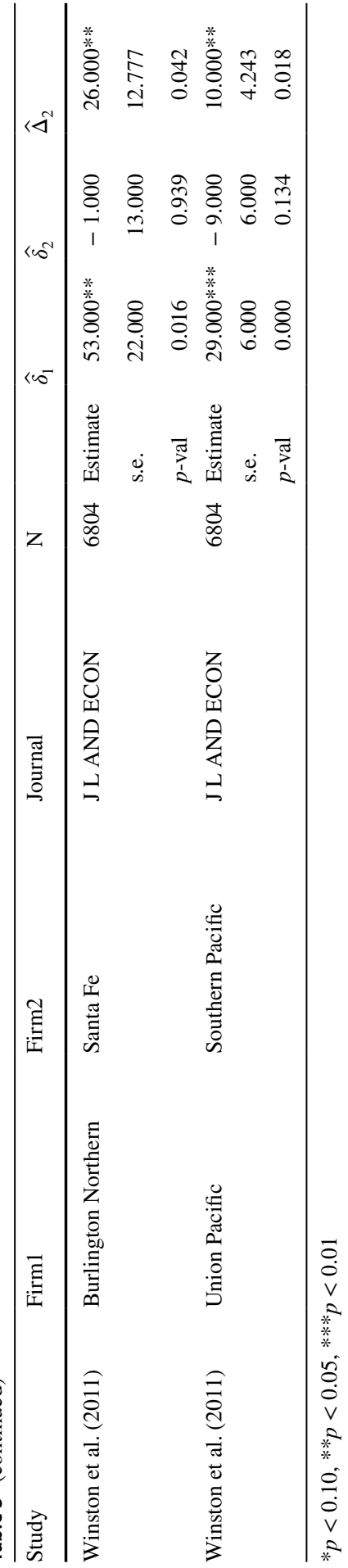


The main message of this simple exercise was to highlight that using the wrong model (pooled instead of unpooled) would have led to the wrong conclusion about the merger in $40 \%$ of the cases. Of course the best way to show the implications of using a pooled model would be to examine all of the studies that use the pooled model and re-estimate them using the unpooled model. The problem is, that we do not have any knowledge on the per-period price variation in these papers (and have no access to the data used). For this reason we turn to a set of Monte Carlo simulations to demonstrate the gravity of the problem.

\section{Simulations}

In the following we simulate a set of cases, where we know how prices evolve postmerger. The objective of this exercise is to gauge how likely it is that using the pooled model leads to the wrong conclusion on the effect of the merger. We consider the following hypothetical cases. (1) Where following an initial post-merger price increase, prices revert to pre-merger levels; (2) Where post-merger prices do not increase immediately after the merger but they do within a reasonable amount of time; (3) Where the merger is followed by an immediate price drop, which then disappears; and (4) Where the post-merger price change is constant over multiple periods.

\subsection{Simulation Framework Explained}

First we simulate the price data. We associate a unitary average value to prices, as if prices were normalised to the average price. In this way we can think of proportional changes, and avoid the use of logs. Then we draw a vector of iid values for the error term from a normal distribution with mean 0 and a value of standard deviation that results in proportional changes in price. For example a standard deviation of 0.2 would mean that around $68 \%$ of the simulated price data would be less than $20 \%$ away from its mean (allowing at most a $40 \%$ price change within the analysed period), and there would be $27 \%$ chance that prices diverge by $20-40 \%$ from the mean (allowing at most a $80 \%$ price change within the analysed period). As we are analysing a relatively short time period (two years) we think this is a reasonable working assumption, it is less likely-although still possible under the assumption of $\mathrm{sd}=0.2$ - that prices would increase or drop by a larger extent within such a short time period. For this reason we use 0.2 as our starting point but we provide the simulation results for other values in Fig. 3 in the "Appendix". The price data are generated with the use of the unpooled model specification that is displayed in Eq. (1a). As our interest is on the DiD coefficients $\delta_{1}$ and $\delta_{2}$, we set all other coefficients to zero.

We maintain the simplifying assumption that there are $T_{R}=2$ post-merger periods (and one pre-merger period), and that each period equals a calendar year. This works for expositional purposes but also in more than $2 / 3$ of the merger retrospective studies in our sample, only two post-merger periods were looked at. Of course, 
the simulations can easily be generalised to any $T_{R}>2$. We also assume that there are $T$ time series observations in each period. For example, if we have daily price data, then $T=365$. Finally we assume that there are $M$ markets that are analysed. This is the cross-sectional dimension of our data.

Next, we use the simulated price vector to estimate the parameters of the model by OLS for both the unpooled-Eq. (1a)_and the pooled models, Eq. (1b). We record the estimated unpooled coefficient $\widehat{\delta}_{2}$ and pooled coefficient $\widehat{\Delta}_{2}$ and test if they are different from zero using a $t$ test (at a significance level of 5\%). ${ }^{17}$ We record the results of the $t$ tests. We then repeat this 1000 times. Finally we compare the proportion of cases where a statistically significant price change is estimated for the pooled and the unpooled models. An important caveat has to be made here. In the simulations below we assume that any non-zero (positive) post-merger price change is harmful. Of course in reality most competition authorities operate with a 'safe harbour' (for example 5\%), below which the price increase is assumed to be small enough to be ignored. One could easily re-run the simulations assuming a harm benchmark that is different from what we currently use).

\subsubsection{Wrongly Concluding that a Merger Should have been Intervened}

We first view the case of a merger that should be considered unharmful because the second post-merger period price is the same as the pre-merger price. In generating the price data therefore we ensure that $\delta_{2}=0$ and allow $\delta_{1}$ to take on any value between zero and a $20 \%$ price increase: $\delta_{1}=[0,0.2]$. Because $\Delta_{2}=\left(\delta_{1}+\delta_{2}\right) / 2$, it is clear that the pooled model estimates a price increase every time $\delta_{1}>0$, and could lead to the conclusion that there was insufficient intervention by the antitrust agency. Using the unpooled model we would correctly estimate that $\delta_{2}=0$ : there was no need for (further) intervention. ${ }^{18}$ Moreover, the standard error of $\widehat{\Delta}_{2}$ will be different from the standard errors of $\hat{\delta}_{1}$ and $\hat{\delta}_{2}$ (simply because the dummy variable $D_{2}$ pools the observations where $d_{1}=1$, or $d_{2}=1$ ). Our simulations show how much this difference in the mean of $\hat{\delta}_{1}$ leads to the wrong conclusion about the merger.

Figure 1a displays the relative inaccuracy of the pooled model in comparison to the unpooled model: the probability of wrongly concluding in the pooled model that the merger intervention was insufficient-prices increased-minus the same probability in the unpooled model. The four lines represent four specific types of data: $T$ refers to the number of time-series observations, and $M$ refers to the number of cross-sections (markets). The data are time series dominated where $T=100$, and $M=10$, and cross-section dominated where $M=100$ and $T=10$.

\footnotetext{
17 As was implied earlier, we focus on the second period coefficient as for the purposes of merger analysis, this has more importance. A merger with an immediate price increase that disappears by the second period should not warrant intervention. Similarly, a merger with no price increase in the first but a price increase in the second period should be considered harmful.

18 Although even in this case it would (approximately) incorrectly estimate a price-increase in $2.5 \%$ of the cases (as we are using a two-tail $95 \%$ significance test).
} 


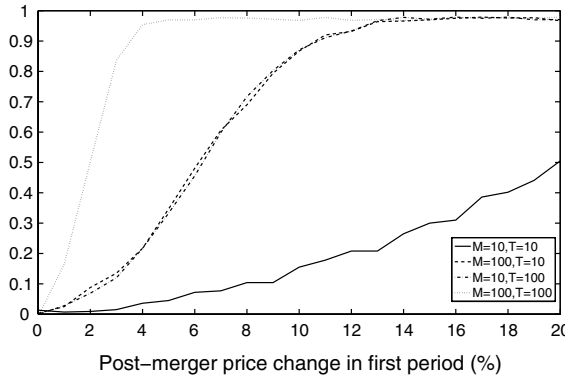

(a) $\delta_{1}=[0,0.2]$ and $\delta_{2}=0$

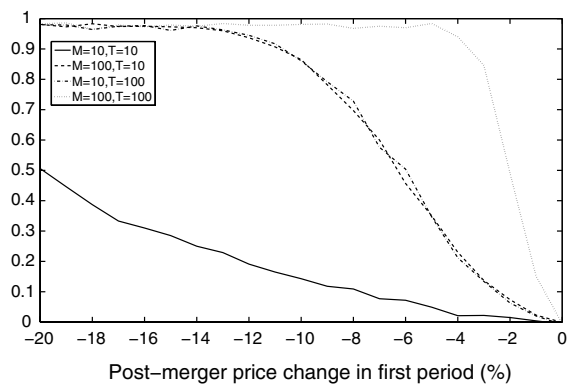

(c) $\delta_{1}=[-0.2,0]$ and $\delta_{2}=0.05$

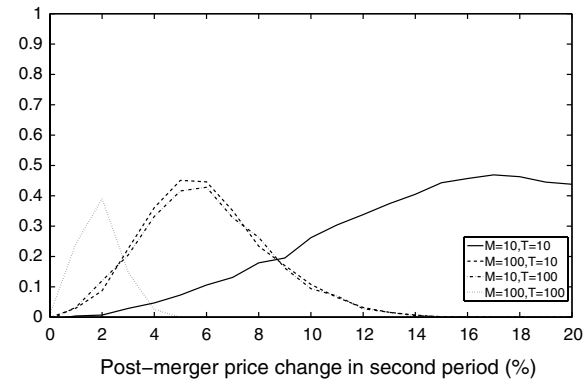

(b) $\delta_{1}=0$ and $\delta_{2}=[0,0.2]$

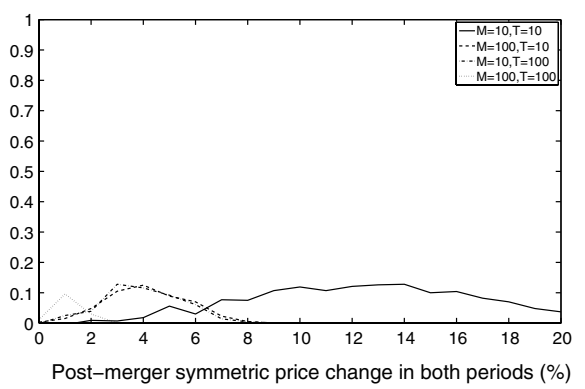

(d) $\delta_{1}=\delta_{2}=[0,0.2]$

Fig. 1 Probability of drawing wrong conclusions on the merger when using the pooled sample

We can see that as $\delta_{1}$ increases, the probability of incorrectly concluding that the merger was harmful-that the intervention was insufficient-increases, and this is more pronounced when we have a larger sample. This is as expected: With small samples, the estimated coefficients have a higher standard error, and consequently they are less likely to be significantly different from zero in both samples. As the sample size increases the $\widehat{\Delta}_{2}$ standard errors decrease and the hypothesis tests become more likely to be statistically significant: in this case predicting that the merger increased prices despite the fact that this price increase disappeared by the second period. The level of the probability of an erroneous conclusion is striking. When a large sample of data is available (such is the case in the analyses of petroleum mergers), even a $4 \%$ increase in the first year after the merger is enough for the pooled model to conclude wrongly (at 95\% significance) that the merger increased prices despite the fact that prices reverted to pre-merger level in the second year. Put differently, in the previous studies where the pooled model was used and it estimated that the merger increased prices, there was a realistic chance that this price increase disappeared as early as the second year after the merger.

\subsubsection{Wrongly Concluding That the Merger Did Not Need Intervention}

Now consider the opposite scenario, where the merger increased prices, but only with a short delay (i.e., no price increase in the first year, and a price increase in the 
second year following the merger, $\delta_{1}=0$, and $\delta_{2}>0$ ). Estimating $\widehat{\Delta}_{2}$ would always give a positive coefficient, therefore it would appear that even the pooled model would be able to detect that the merger would have needed intervention (because it increased prices). Figure $1 \mathrm{~b}$ shows that this is not always the case. In fact, it is highly possible that the pooled model would estimate that $\widehat{\Delta}_{2}$ is not significantly different from zero and conclude, wrongly, that the merger did not increase prices. Relative to the unpooled model this could happen in up to $40 \%$ of the cases. For example, even if one has rich time-series and cross-sectional data, the pooled sample would be unable to identify mergers where prices increased by up to $3 \%$ in the second year after the merger. With smaller samples the problem would be even more pronounced. For example, with monthly data over 10 cross-sections (which is a very common data endowment) the pooled model would wrongly conclude that a merger did not increase prices even when the second year price increase was $10 \%$; and in that case the larger is the second period price increase, the more pronounced is the wrong decision.

\subsubsection{Wrongly Concluding That the Merger Reduced Prices}

There are a large number of merger retrospectives that conclude that the merger resulted in a price reduction. To illustrate the weakness of using the pooled model in these cases, we present a scenario where the merger increased prices in the second post-merger year by $5 \%$. In any interpretation these mergers should be considered harmful and the conclusion would be that (more) intervention would have been warranted. However, when using the pooled model, the pooled dummy variable coefficient $\left(\widehat{\Delta}_{2}\right)$ will be negative if there was a sufficiently large price-drop in the first period. The expected value of $\widehat{\Delta}_{2}$ is zero where there was a price drop of $5 \%$ in the first period, therefore one would expect that the pooled model will lead to a wrong conclusion only if $\delta_{1}<-5$.

Figure 1c shows that-as expected-if the first period price drop is sufficiently large then the coefficient on the pooled dummy variable will always wrongly conclude that the merger reduced prices. With a large sample (daily prices over 100 cross-sections) this will almost always be the case.

\subsubsection{Mergers with Constant Post-merger Price Effect}

In this final scenario we examine how the pooled and unpooled samples perform where the price effect of the merger is constant $\left(\delta_{1}=\delta_{2}\right)$. It would appear that there should not be any difference between the two estimates, because $\Delta_{2}=\delta_{1}=\delta_{2}$, but again the difference in standard errors will have a role to play. Figure 1d shows the relative probability of finding a price increase is significant when post-merger prices are constant, using a pooled model. Put differently, this is the probability that the unpooled sample concludes that the merger did not increase prices even though the pooled model concludes that it did. The intuition is simple: The estimated pooled dummy variable coefficient $\widehat{\Delta}_{2}$ has a lower standard error where $\delta_{1}=\delta_{2}$, and is therefore more likely to estimate that the price increase is significantly different 
from zero. This relative weakness of the unpooled model is small; but, when one deals with small samples, it could be around 10 percent.

The main message of this final point is important for research design. We would argue that the researcher should run the unpooled model and estimate yearly price effects, but if these are of similar magnitude (and non-significant) then it is good strategy to also run the pooled model (or at least conduct an F-test for the joint significance of the yearly dummy variables). If the pooled model returns significant price effects or if the yearly dummy variables are jointly significant, then one could conclude that although the annual price effects are not individually significant, the overall post-merger effect is.

\section{Conclusions}

Merger retrospectives are typically conducted to inform policy-makers about the fitness of merger control for filtering and remedying price increasing mergers. For this reason the conclusion as to whether a merger increased prices is crucial. We showed above that the probability of making the wrong conclusion is high if the wrong empirical specification is used. If the antitrust agency predicted that the merger would lead to a temporary price hike, but prices would eventually (within a reasonable length of time) revert to pre-merger levels, then it would probably refrain from intervention. Therefore the retrospective study should not only examine how prices change on average, instead, the study should also estimate whether (and how quickly) prices revert to pre-merger levels.

We find that more than $85 \%$ (58 mergers) of previous studies estimate postmerger average price effects (pooled sample), and per-period (annual) effects were estimated for only 10 mergers (unpooled sample). We argue that this is a mistaken approach as it masks information on post-merger price dynamics that would be crucial for the assessment of the merger. By running a set of Monte Carlo simulations we show that estimating the mean post-merger price effect might lead to erroneous conclusions on the effect of the merger. Our simulations demonstrate that potentially all studies (using the pooled sample) that concluded that the merger led to a price increase, could have been wrong, and that the price increase actually disappeared within a reasonable time. This is more likely where the studies had large samples (for example daily price data over large cross-sections). Similarly, up to half of the studies that concluded-based on the pooled sample-that the merger did not increase prices might have been wrong, and in actuality after a short period of unchanged prices, prices went up. Finally, studies that estimate that the merger reduced prices can potentially all be wrong in their conclusion on the merger if the merger was eventually followed by a price increase, but this was preceded by a sufficiently large price drop.

In our view, where data are available to estimate the pooled sample, it should be equally available to estimate yearly effects - this is not about getting longer-spanning data but using a different model specification-and thus gather evidence on how prices evolve post-merger. Not only could this more accurately inform the researcher whether the antitrust authority's intervention was appropriate, but accumulating a 
large mass of these studies could tell us more about the dynamics of post-merger market self-correction.

An estimation that uses the unpooled sample does much more than just show whether the merger significantly increased prices in the $K$-th period. It gives the researcher highly valuable information on the dynamics of post-merger prices. This is important not only because one cares about whether prices eventually revert to pre-merger levels, but it also allows the identification of whether prices remain stable or unstable over time. These two outcomes can have very different welfare implications and would lead to different policy conclusions. The literature on the welfare implication of price stability can offer us more general insights, starting with simplistic models of Waugh (1944), and followed by the highly influential work of Newbery and Stiglitz (1979) and Stiglitz (1981). From this tradition we can find a rich body of works that examine the effect of price stability with realistic assumptions about consumer utility functions and introducing risk-attitude (Turnovsky et al. 1980). These models show that-depending on consumers' risk-aversenessstable prices may mean lower or higher associated consumer surplus than do volatile prices. However, the important point is that the welfare implications of stable and volatile post-merger prices are likely to be different, therefore it matters which empirical model is used for estimating the effect of mergers on these prices.

Acknowledgements We are grateful for useful comments to Silvi Berger, Steve Davies, John Kwoka, participants of EARIE (2017), and the CCP Norwich Seminar Series. The support of the Centre for Competition Policy is gratefully acknowledged. The usual disclaimer applies.

Open Access This article is distributed under the terms of the Creative Commons Attribution 4.0 International License (http://creativecommons.org/licenses/by/4.0/), which permits unrestricted use, distribution, and reproduction in any medium, provided you give appropriate credit to the original author(s) and the source, provide a link to the Creative Commons license, and indicate if changes were made.

\section{Appendix: Papers Used to Create Sample}

\section{EU Sample}

1. Aguzzoni, L., Argentesi, E., Ciari, L., Duso, T., \& Tognoni, M. (2016). Ex post merger evaluation in the UK retail market for books. The Journal of Industrial Economics, 64(1), 170-200.

2. Aguzzoni, L., Buehler, B., Di Martile, L., Ecker, G., Kemp, R., Schwarz, A., \& Stil, R. (2015). Ex-post analysis of two mobile telecom mergers: T-Mobile/tele. ring in Austria and T-mobile/Orange in the Netherlands. Report of the European Commission, DG COMP.

3. Aguzzoni, L., Argentesi, E., Buccirossi, P., Ciari, L., Duso, T., Tognoni, M., \& Vitale, C. (2014). A Retrospective Merger Analysis in the UK Videogame Market. Journal of Competition Law and Economics, 10(4), 933-958. 
4. Aguzzoni, L., Argentesi, E., Buccirossi, P., Ciari, L., Duso, T., Tognoni, M., \& Vitale, C. (2011). The ex-post evaluation of two merger decisions. A report prepared for the UK Competition Commission.

5. Allain, M. L., Chambolle, C., Turolla, S., \& Villas-Boas, S. B. (2017). Retail mergers and food prices: Evidence from France. The Journal of Industrial Economics, 65(3), 469-509.

6. Argentesi, E., Banal-Estañol, A., Seldeslachts, J., \& Andrews, M. (2017). A retrospective evaluation of the GDF/Suez merger: Effects on gas hub prices. DIW Discussion Papers.

7. Björnerstedt, J. \& Verboven, F. (2016). Does merger simulation work? Evidence from the Swedish analgesics market. American Economic Journal: Applied Economics, 8(3), 125-64.

8. Choné, P. \& Linnemer, L. (2012). A Treatment Effect Method for Merger Analysis with an Application to Parking Prices in $\mathrm{P}$ aris. The Journal of industrial economics, 60(4), 631-656.

9. Csorba, G., G. Koltay \& D. Farkas (2011). Separating the ex post effects of mergers: An analysis of structural changes on the Hungarian retail gasoline market. Discussion Papers, Hungarian Academy of Sciences.

10. Friberg, R., \& Romahn, A. (2015). Divestiture requirements as a tool for competition policy: A case from the Swedish beer market. International journal of industrial organization, 42, 1-18.

11. Kemp, R. G., Kersten, N., \& Severijnen, A. M. (2012). Price effects of dutch hospital mergers: an ex-post assessment of hip surgery. De Economist, 160(3), 237-255.

12. Office of Fair Trading (2014). Shell-Rontec: An evaluation of the OFT's conditional clearance of the merger.

13. Perdiguero, J. \& J. L. Jiménez González (2014). Mergers and difference-indifference estimator: Why firms do not increase prices? European Journal of Law and Economics, 45(2), 285-311.

\section{US Sample}

1. Armantier, O., \& Richard, O. (2006). Evidence on pricing from the Continental Airlines and Northwest Airlines code-share agreement. Advances in airline economics, 1, 91-108.

2. Ashenfelter, O. C., Hosken, D. S., \& Weinberg, M. C. (2013). The price effects of a large merger of manufacturers: A case study of Maytag-Whirlpool. American Economic Journal: Economic Policy, 5(1), 239-61.

3. Ashenfelter, O., \& Hosken, D. (2010). The effect of mergers on consumer prices: Evidence from five mergers on the enforcement margin. The Journal of Law and Economics, 53(3), 417-466.

4. Bamberger, G., \& Carlton, D. W. (1999). Antitrust and higher education: MIT financial aid (1993). The antitrust revolution: Economics, competition and policy, 264-285. 
5. Barton, D. M., \& Sherman, R. (1984). The price and profit effects of horizontal merger: a case study. The Journal of Industrial Economics, 165-177.

6. Borenstein, S. (1985). Airline mergers, airport dominance, and market power. The American Economic Review, 80(2), 400-404.

7. Gayle, P. G. (2008). An empirical analysis of the competitive effects of the delta/ continental/northwest code-share alliance. The Journal of Law and Economics, 51(4), 743-766.

8. Guardado, J. R., Emmons, D. W., \& Kane, C. K. (2013). The price effects of a large merger of health insurers: A case study of UnitedHealth-Sierra. Health Management, Policy and Innovation, 1(3), 16-35.

9. Haas-Wilson, D., \& Garmon, C. (2011). Hospital mergers and competitive effects: Two retrospective analyses. International Journal of the Economics of Business, 18(1), 17-32.

10. Hosken, D., Silvia, L., \& Taylor, C. (2011). Does concentration matter? Measurement of petroleum merger price effects. American Economic Review, 101(3), 45-50.

11. Karikari, J. A., Brown, S. M., \& Nadji, M. (2002). The Union Pacific/Southern Pacific railroads merger: Effect of trackage rights on rates. Journal of Regulatory Economics, 22(3), 271-285.

12. Kwoka, J., \& Shumilkina, E. (2010). The price effect of eliminating potential competition: Evidence from an airline merger. The journal of industrial economics, 58(4), 767-793.

13. Luo, D. (2014). The price effects of the Delta/Northwest airline merger. Review of Industrial Organization, 44(1), 27--48.

14. McCabe, M. J. (2002). Journal pricing and mergers: a portfolio approach. American Economic Review, 92(1), 259-269.

15. McCabe, M. J. (2004). Law serials pricing and mergers: A portfolio approach. Contributions in Economic Analysis \& Policy, 3(1).

16. Morrison, S. A. (1996). Airline mergers: A longer view. Journal of Transport Economics and Policy, 237-250.

17. Peters, C. (2006). Evaluating the performance of merger simulation: Evidence from the US airline industry. The Journal of law and economics, 49(2), 627-649.

18. Schumann, L., Rogers, R. P., \& Reitzes, J. D. (1992). Case studies of the price effects of horizontal mergers. Bureau of Economics, Federal Trade Commission.

19. Simpson, J., \& Taylor, C. (2008). Do gasoline mergers affect consumer prices? The Marathon Ashland petroleum and Ultramar Diamond Shamrock transaction. The Journal of Law and Economics, 51(1), 135-152.

20. Taylor, C. T., \& Hosken, D. S. (2007). The economic effects of the MarathonAshland joint venture: the importance of industry supply shocks and vertical market structure. The Journal of Industrial Economics, 55(3), 419-451.

21. Taylor, C., \& D. Hosken (2004). Energy markets: Effects of mergers and market concentration in the US petroleum industry. GAO-04-96, Washington, DC.

22. Silvia, L., \& Taylor, C. T. (2013). Petroleum mergers and competition in the northeast United States. International journal of the economics of business, 20(1), 97-124.

23. Tenn, S. (2011). The price effects of hospital mergers: a case study of the Sutter-Summit transaction. International Journal of the Economics of Business, 18(1), 65-82. 
24. Thompson, A. (2011). The effect of hospital mergers on inpatient prices: a case study of the New Hanover-Cape Fear transaction. International Journal of the Economics of Business, 18(1), 91-101.

25. Werden, G. J., Joskow, A. S., \& Johnson, R. L. (1991). The effects of mergers on price and output: Two case studies from the airline industry. Managerial and Decision Economics, 12(5), 341-352.

26. Winston, C., Maheshri, V., \& Dennis, S. M. (2011). Long-run effects of mergers: The case of US western railroads. The Journal of Law and Economics, 54(2), 275-304.

\section{Descriptive Statistics}

Although not directly relevant for the main argument in this paper, we can reveal how the estimates in our meta-analysis vary across industries. Table 4 shows the industry average price effects (weighted by the inverse t-stat). Figure 2 shows the empirical distribution of these estimates for the industries with the largest number of estimates.

Table 4 Market-, and merger-level estimates and price variation by industry

\begin{tabular}{|c|c|c|c|c|c|c|}
\hline \multirow[t]{2}{*}{ Industry } & \multicolumn{3}{|c|}{ Market level estimates } & \multicolumn{3}{|c|}{ Merger level estimates } \\
\hline & $\mathrm{N}$ & es & se & $\mathrm{N}$ & es & se \\
\hline Airlines & 28 & 1.936 & 0.378 & 14 & 2.405 & 0.215 \\
\hline Books & 11 & 0.022 & 0.156 & 2 & 1.028 & 0.584 \\
\hline Brewing & 7 & -1.915 & 0.457 & 1 & -1.557 & 1.157 \\
\hline Car Parking & 32 & 2.581 & 0.382 & 1 & 1.866 & 1.938 \\
\hline Cement & 2 & -27 & 8.583 & 1 & -27 & 12.130 \\
\hline Computer games & 2 & -19.087 & 3.713 & 1 & -19.083 & 5.251 \\
\hline Corrugating medium & 2 & 0.950 & 4.727 & 1 & 0.950 & 6.672 \\
\hline Diazo microfilm & 18 & 11.100 & 1.445 & 1 & 11.100 & 5.394 \\
\hline Energy & 1 & -6 & 1.255 & 1 & -6 & 1.255 \\
\hline Health care & 1 & 14.683 & 5.548 & 1 & 14.683 & 5.548 \\
\hline Home appliances & 16 & 0.617 & 0.492 & 1 & -0.175 & 1.750 \\
\hline Hospitals & 338 & 11.628 & 0.526 & 10 & 6.822 & 2.301 \\
\hline Law journal & 11 & 13.267 & 1.155 & 4 & 11.069 & 1.502 \\
\hline Petroleum & 54 & -2.039 & 0.097 & 17 & -0.361 & 0.218 \\
\hline Pharmaceuticals & 9 & 33.271 & 0.299 & 1 & 18.489 & 0.979 \\
\hline Rail & 30 & 0.951 & 1.584 & 3 & 1.111 & 4.662 \\
\hline Ready-to-eat cereal & 11 & 9.346 & 0.564 & 1 & 5.164 & 1.455 \\
\hline Scientific journal & 3 & 5.544 & 1.619 & 1 & 4.333 & 2.723 \\
\hline Spirits & 28 & 0.155 & 0.158 & 1 & -0.679 & 0.889 \\
\hline Supermarkets & 1 & 0.004 & 0.028 & 1 & 0.004 & 0.028 \\
\hline Telecoms & 2 & 1.000 & 3.307 & 2 & 1.000 & 3.307 \\
\hline Titanium dioxide & 1 & 28 & 12.219 & 1 & 28 & 12.219 \\
\hline Vesticular microfilm & 18 & 22.839 & 2.329 & 1 & 22.839 & 8.869 \\
\hline Total & 626 & 11.164 & 0.255 & 68 & 4.189 & 0.320 \\
\hline
\end{tabular}




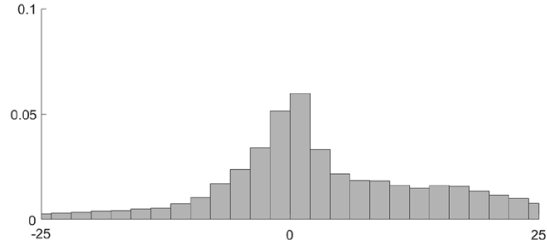

(a) market level - aggregate

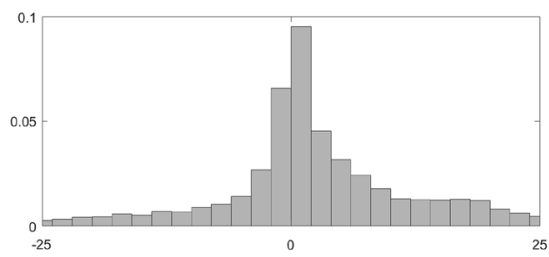

(c) merger level - aggregate

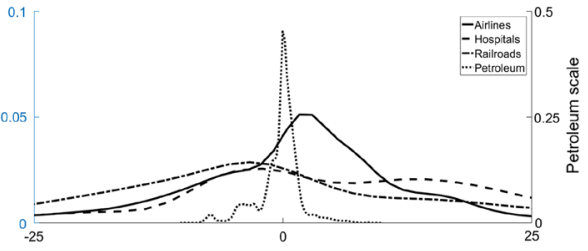

(b) market level - by industry

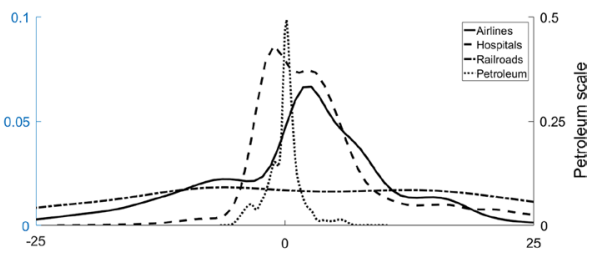

(d) merger level - by industry

Fig. 2 Empirical distribution of price effect estimates for market and merger level data (\% price change)

Airlines, hospitals, and petroleum are the most researched areas, which is probably due to data availability. From these estimates only, it appears that petroleum mergers on average do not increase prices (the density curves in Fig. 2 also show that the estimates are very concentrated around zero). Rail mergers are typically not anti-competitive. On the other hand airline mergers seem to be price-increasing. Finally, the bimodal density of hospital estimates suggests two groups of hospital mergers, one clearly price-reducing, and another clearly price-increasing.

\section{Additional Figures}

\section{The Effect of Serial Correlation and Clustering}

In the main text we have assumed that there is no serial correlation in our simulated price data. We now relax on that assumption. Bertrand et al. (2004) show that as a result of serial correlation OLS standard errors badly underestimate the standard deviation of the estimators. This means, that in the case of positive serial correlation difference-in-differences studies (using OLS) would falsely estimate significant intervention effects. For this reason we look at how having serially correlated price data affects the above findings.

We define the error term as an AR(1) model with serial-correlation parameter $\rho$ set to 0.8. We first estimate the pooled and the unpooled samples by OLS and then we cluster the standard deviation of the estimated coefficients and re-estimate both models. ${ }^{19}$ We confine the simulations to two cases, first, where the cross-sections are

19 The cluster-robust formula for the estimated variance-covariance of the OLS estimator is: $\widehat{V}(\hat{\boldsymbol{\theta}})=\left(\mathbf{X}^{\prime} \mathbf{X}\right)^{-1}\left(\sum_{m=1}^{M} \mathbf{X}_{m}^{\prime} \widehat{\mathbf{u}}_{m} \widehat{\mathbf{u}}_{m}^{\prime} \mathbf{X}_{m}\right)\left(\mathbf{X}^{\prime} \mathbf{X}\right)^{-1}$, with $\boldsymbol{\theta}$ including all coefficients. 


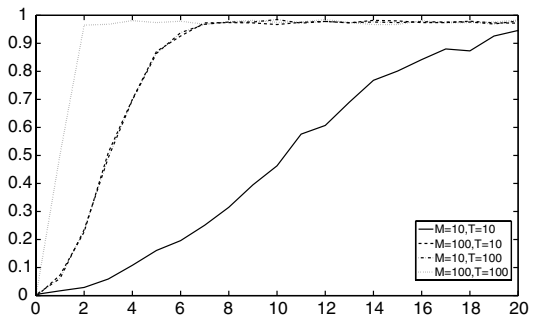

Post-merger price change in first period (\%)

(a) $\delta_{1}=[0,0.2]$ and $\delta_{2}=0, \mathrm{sd}=0.1$

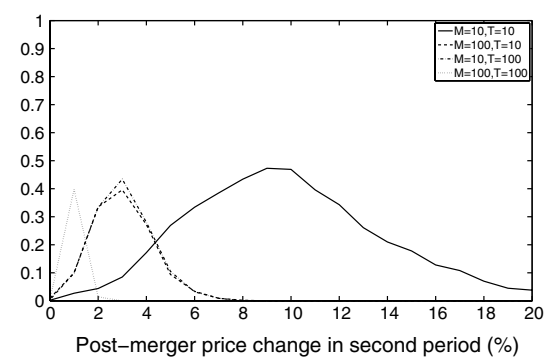

(c) $\delta_{1}=0$ and $\delta_{2}=[0,0.2], \mathrm{sd}=0.1$

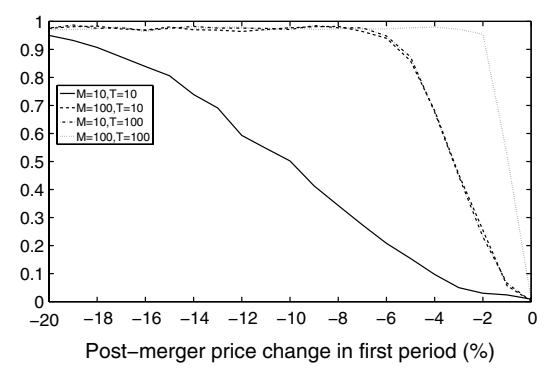

(e) $\delta_{1}=[-0.2,0]$ and $\delta_{2}=0.05, \mathrm{sd}=0.1$

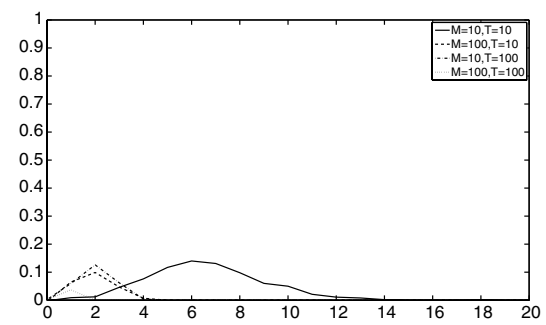

Post-merger symmetric price change in both periods (\%)

(g) $\delta_{1}=\delta_{2}=[0,0.2], \mathrm{sd}=0.1$

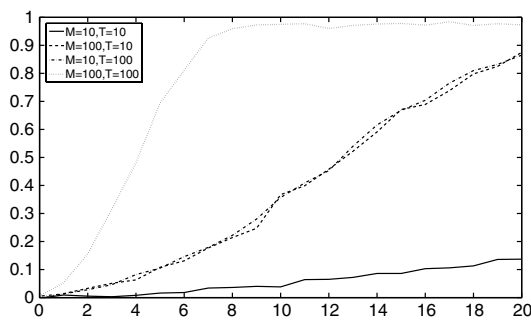

Post-merger price change in first period (\%)

(b) $\delta_{1}=[0,0.2]$ and $\delta_{2}=0, \mathrm{sd}=0.4$

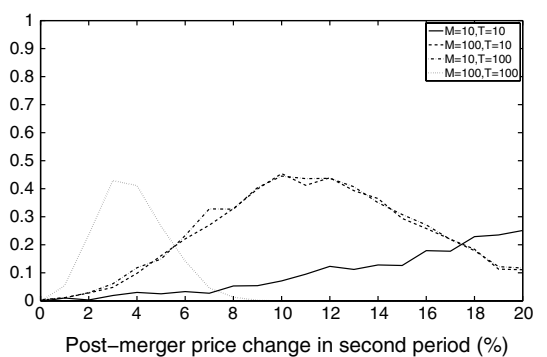

(d) $\delta_{1}=0$ and $\delta_{2}=[0,0.2], \mathrm{sd}=0.4$

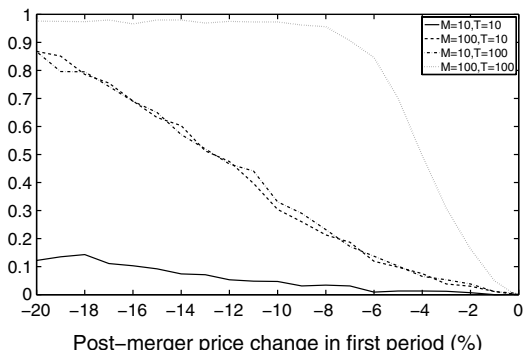

(f) $\delta_{1}=[-0.2,0]$ and $\delta_{2}=0.05, \mathrm{sd}=0.4$

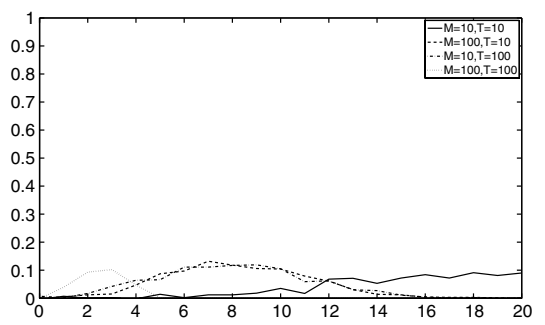

Post-merger symmetric price change in both periods $(\%)$

(h) $\delta_{1}=\delta_{2}=[0,0.2] \mathrm{sd}=0.4$

Fig. 3 Probability of drawing wrong conclusions on the merger when using the pooled sample-assuming different levels of standard deviation 


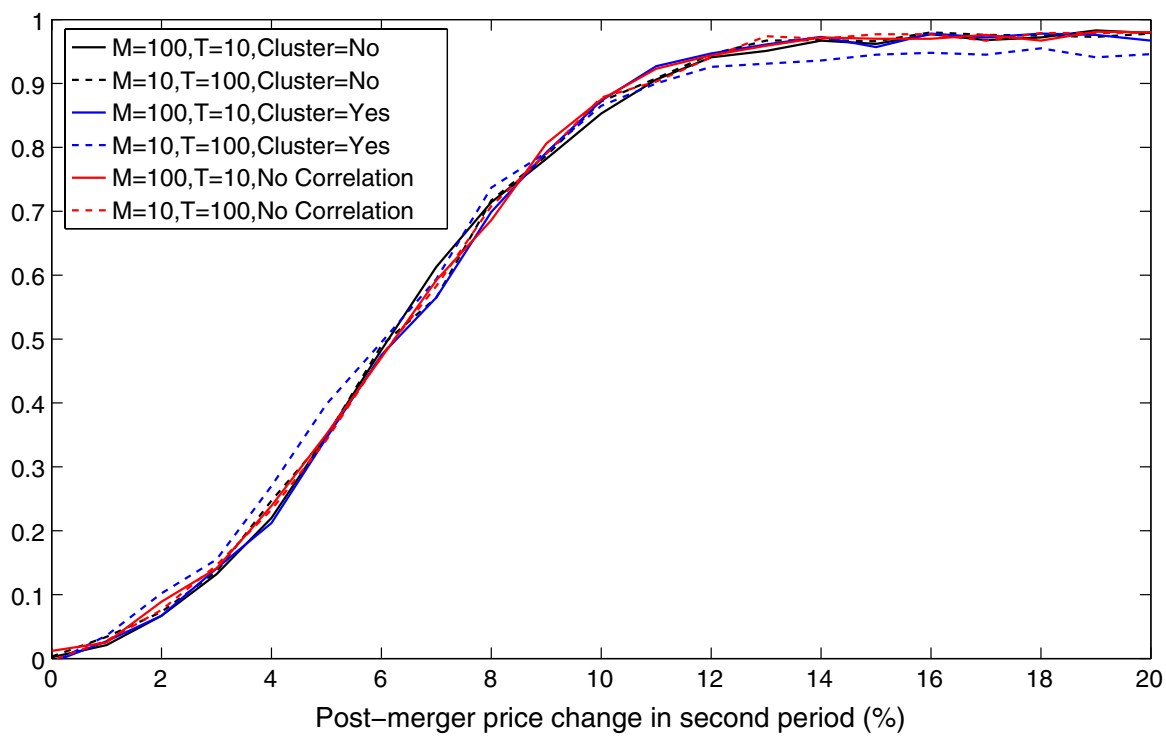

Fig. 4 Type I error: price change in period 1 and no price change in period 2 (clustered standard errors)

large and time period is small, and vice versa. In each case we plot the difference in the probability of estimating a significant price increase in the pooled sample, relative to the unpooled sample. Figure 4 plots how much more likely it is for the pooled sample to estimate a significant price increase than the unpooled sample.

The figure shows that our initial findings (Fig. 1a) still hold even with serially correlated data. In fact we find that serial correlation (or the clustering of standard errors) does not noticeably affect the difference between the pooled and the unpooled samples. We repeated these experiments for the other scenarios and found the same result.

\section{Verifying Equivalence Between Average Unpooled and Pooled DiD Estimators}

Assume a balanced panel with cross-section of length $M$ and time series of length $T=T_{R}+1$, so that there is a period before the merger (period $T_{L}=1$ ) and $T_{R}$ periods after the merger with no time fragments. Postulate that half of the cross-section is used as control and the other half as treatment, so that there are $M / 2$ units in each group. Without loss of generality and to ease the readiness of the proof, we model a simplified version of equations (1a) and (1b):

$$
p_{m t}=\beta_{0}+\sum_{k=1}^{T_{R}} \delta_{k} d_{k} W_{m}+\varepsilon_{m t}
$$




$$
p_{m t}=\beta_{0}+\Delta_{T_{R}} D_{T_{R}} W_{m}+\varepsilon_{m t} .
$$

We analyse first Eq. (5a). Let $\underset{M T \times T}{X}$ indicate the matrix of all covariates, which in this case corresponds to the constant and $T_{R} \equiv T-1$ time dummy variables interacted with the treatment dummy variable. The OLS estimator of the above regression is:

$$
\hat{\theta}=\left[\begin{array}{c}
\hat{\beta}_{0} \\
\hat{\delta}_{1} \\
\vdots \\
\hat{\delta}_{T_{R}}
\end{array}\right]=\left(X^{\prime} X\right)^{-1} X^{\prime} p
$$

Let's partition $\left(X^{\prime} X\right)^{-1}$ and $X^{\prime} p$ to be, respectively:

$$
\left(X^{\prime} X\right)^{-1}=\left[\begin{array}{ll}
A & B \\
C & D
\end{array}\right]^{-1}
$$

and

$$
X^{\prime} p=\left[\begin{array}{c}
P \\
P_{1} \\
\cdots \\
P_{T_{R}}
\end{array}\right] \equiv\left[\begin{array}{c}
\sum_{m} \sum_{t} p_{m t} \\
\sum_{m} p_{m 1} W_{m} \\
\ldots \\
\sum_{m} p_{m T_{R}} W_{m}
\end{array}\right] .
$$

Then, based on (5a) we associate the elements to $A=M T, B=\left[\frac{M}{2}, \frac{M}{2}, \ldots, \frac{M}{2}\right]$, $C=B^{\prime}$, and

$$
D \equiv\left(\begin{array}{cccc}
\frac{M}{2} & 0 & 0 & 0 \\
0 & \frac{M}{2} & 0 & 0 \\
& \cdots & & \\
0 & 0 & 0 & \frac{M}{2}
\end{array}\right) .
$$

Defining with $e$ a $T_{R} \times 1$ column vector of ones, and recalling that the inverse of the partitioned matrix (7) is,

$$
\left[\begin{array}{ll}
A & B \\
C & D
\end{array}\right]^{-1}=\left[\begin{array}{cc}
\left(A-B D^{-1} C\right)^{-1} & -\left(A-B D^{-1} C\right)^{-1} B D^{-1} \\
-D^{-1} C\left(A-B D^{-1} C\right)^{-1} & D^{-1}+D^{-1} C\left(A-B D^{-1} C\right)^{-1} B D^{-1}
\end{array}\right],
$$

we have that $B D^{-1}=e^{\prime}, D^{-1} C=e, B D^{-1} C=\frac{M}{2}(T-1)$, and $A-B D^{-1} C=$ $\frac{M}{2}(T+1)$. Therefore, the cells of the partitioned matrix in (10) are:

$$
\left[\begin{array}{ll}
A & B \\
C & D
\end{array}\right]^{-1}=\frac{2}{M(T+1)}\left[\begin{array}{cc}
1 & -e^{\prime} \\
-e & (T+1) I+e e^{\prime}
\end{array}\right]
$$


implying that

$$
\left[\begin{array}{c}
\hat{\beta}_{0} \\
\hat{\delta}_{1} \\
\vdots \\
\hat{\delta}_{T_{R}}
\end{array}\right]=\frac{2}{M(T+1)}\left[\begin{array}{c}
P-\sum_{k=1}^{T_{R}} P_{k} \\
(T+1) P_{1}+\sum_{k=1}^{T_{R}} P_{k}-P \\
\vdots \\
(T+1) P_{T_{R}}+\sum_{k=1}^{T_{R}} P_{k}-P
\end{array}\right] .
$$

Now, consider the specification in Eq. (5b). From above, we have that $X^{\prime} p$ modifies to:

$$
X^{\prime} p=\left[\begin{array}{c}
P \\
\sum_{k=1}^{T_{R}} P_{k}
\end{array}\right] \equiv\left[\begin{array}{c}
\sum_{m} \sum_{t} p_{m t} \\
\sum_{m} \sum_{t \geq 1} p_{m t} W_{m}
\end{array}\right]
$$

and now $B=C=D=\frac{M}{2}(T-1)$ and $A$ of course remains the same, $A=M T$, leading to

$$
\left[\begin{array}{ll}
A & B \\
C & D
\end{array}\right]^{-1}=\frac{2}{M(T+1)}\left[\begin{array}{cc}
1 & -1 \\
-1 & \frac{2 T}{T-1}
\end{array}\right] .
$$

Yielding,

$$
\left[\begin{array}{c}
\hat{\beta}_{0} \\
\hat{\Delta}_{2}
\end{array}\right]=\frac{2}{M(T+1)}\left[\begin{array}{c}
P-\sum_{k=1}^{T_{R}} P_{k} \\
\frac{2 T}{T-1} \sum_{k=1}^{T_{R}} P_{k}-P
\end{array}\right],
$$

which verifies that $\frac{1}{T-1} \sum_{k=1}^{T_{R}} \hat{\delta}_{k}=\hat{\Delta}_{2}$.

\section{References}

Bertrand, M., Duflo, E., \& Mullainathan, S. (2004). How much should we trust differences-in-differences estimates? The Quarterly Journal of Economics, 119(1), 249-275.

Focarelli, D., \& Panetta, F. (2003). Are mergers beneficial to consumers? Evidence from the market for bank deposits. The American Economic Review, 93(4), 1152-1172.

Kwoka, J. E. (2013). Does merger control work? A retrospective on U.S. enforcement actions and merger outcomes. Antitrust Law Journal, 78(3), 619-650.

Kwoka, J. E. (2014). Mergers, merger control, and remedies: A retrospective analysis of U.S. policy. MIT Press. https://books.google.co.uk/books?id=hMYQBgAAQBAJ.

Mariuzzo, F., Ormosi, P. L., \& Havell, R. (2016). What can merger retrospectives tell us? An assessment of European mergers. CCP Working Paper, 16(4).

Newbery, D. M., \& Stiglitz, J. E. (1979). The theory of commodity price stabilisation rules: Welfare impacts and supply responses. The Economic Journal, 89(356), 799-817.

Stiglitz, J. E. (1981). The theory of commodity price stabilization: a study in the economics of risk. Oxford: Clarendon Press.

Turnovsky, S. J., Shalit, H., \& Schmitz, A. (1980). Consumer's surplus, price instability, and consumer welfare. Econometrica: Journal of the Econometric Society, 48(1), 135-152.

Waugh, F. V. (1944). Does the consumer benefit from price instability? The Quarterly Journal of Economics, 58(4), 602-614. 
Winston, C., Maheshri, V., \& Dennis, S. M. (2011). Long-run effects of mergers: The case of US Western railroads. The Journal of Law and Economics, 54(2), 275-304.

Wolfers, J. (2006). Did unilateral divorce laws raise divorce rates? A reconciliation and new results. The American Economic Review, 96(5), 1802-1820.

Publisher's Note Springer Nature remains neutral with regard to jurisdictional claims in published maps and institutional affiliations. 